\title{
Ovitrampas para Avaliação da Presença de Aedes aegypti (Linnaeus) e Aedes albopictus (Skuse) no Município de Vassouras, Estado do Rio de Janeiro
}

\author{
Alexandre de Araujo Oliveira \& Marise Maleck ${ }^{\bowtie}$
}

Universidade Severino Sombra, e-mail: alexandre.araujo@biologo.bio.br, mmaleck@oi.com.br (Autor para correspondência ${ }^{\varpi}$ )

\author{
EntomoBrasilis 7 (1): 52-57 (2014)
}

\begin{abstract}
Resumo. Aedes aegypti (Linnaeus) e Aedes albopictus (Skuse) são vetores de diversas arboviroses entre elas a febre amarela urbana e a dengue, sendo a última um dos maiores problemas no mundo em cidades que possuem clima quente e úmido. Diante dos consecutivos casos de dengue em Vassouras-RJ foi importante averiguar a presença e comportamento do vetor nas diversas épocas do ano e sua predominância no município. Neste estudo observou-se a presença de Ae. aegypti em 10,44\% e Ae. albopictus em 89,56\% dos 364 ovos que se tornaram viáveis, e sendo o bairro Matadouro, ponto 4, local com maior presença destes culicídeos. Estes dados mostraram que Ae. albopictus está cada vez mais presente na área urbana.
\end{abstract}

Palavras-Chave: Culicidae; Ovitrampas; Levantamento populacional.

\section{Ovitramps for evaluating the presence of Aedes aegypti (Linnaeus) and Aedes albopictus (Skuse) in Vassouras City, State of Rio de Janeiro}

Abstract. Aedes aegypti (Linnaeus) and Aedes albopictus (Skuse) are vectors of many arboviruses including urban yellow fever and dengue, the latter being one of the biggest problems in the world in cities that have hot and humid climate. Having the consecutive cases of dengue in Vassouras, $\mathrm{RJ}$ it was important to ascertain the presence and behavior of the vector in different seasons of year and their predominance in the city. In this study we observed the presence of $10.44 \%$ Ae. aegypti and $89.56 \%$ Ae. albopictus of the 364 viable eggs and being the Matadouro neighborhood (point 4 ), the local with the largest presence of these culicids. These data showed that Ae. albopictus is ever more present in urban areas.

Keywords: Culicidae; Ovitramps; Populational researches.

( s mosquitos do gênero Aedes são considerados vetores de diversas arboviroses como a febre amarela urbana e a dengue, em cidades que possuem clima úmido e quente se tornaram grandes problemas de saúde (TorREs 2005).

O Aedes aegypti (Linnaeus) é um mosquito cosmopolita com ocorrência em climas quentes e úmidos situados entre os paralelos $35^{\circ} \mathrm{N}$ e $35^{\circ} \mathrm{S}$ e sua distribuição também está restrita pela altitude com relevância de ocorrência abaixo de 1.000 metros, entretanto em condições específicas foram encontradas espécimes em altitude de 2.200 metros acima do nível do mar na Colômbia e Índia (WHO 2009). Este culicídeo possui estreita relação com o ser humano, sendo essencialmente urbano, embora encontrado em algumas regiões como zonas rurais afastadas, mas provavelmente introduzidas pelo homem, e acredita-se que o Ae. aegypti seja uma espécie originária da África que chegou a Europa e em seguida à América no inicio das explorações e da colonização do continente (TAUIL 2001). Sua estreita relação com os seres humanos tornou-o altamente adaptável ao ambiente urbano, vindo a ter sua presença com predominância em domicílios e nos abrigos peridomiciliares, possuindo picos de atividades nas primeiras horas do dia e no início do crepúsculo (Souza 2008). No Brasil, o Ae. aegypti foi provavelmente introduzido no período colonial em conjunto com o tráfego de escravos africanos, amplamente intensificado nos séculos XVIII e XIX, e hoje está presente em locais com maior concentração humana e raramente em ambientes semi-silvestres e silvestres (Souza 2008).
Sua importância como vetor da febre amarela no início do século passado o tornou alvo de uma campanha de erradicação com o incentivo da Fundação Rockefeller, essa campanha ocorrida entre os anos de 1923 e 1940 nas cidades litorâneas do nordeste praticamente eliminou o Ae. aegypti, assim como vinha sendo executadas em outros países. Em 1955 o Ae. aegypti foi considerado erradicado, entretanto a campanha perdeu força nos anos posteriores e o Ae. aegypti reapareceu no final da década de 60 (BRAGA \& VALE 2007).

Nos países subdesenvolvidos a migração da população para as cidades a partir da década de 60 , aliada a políticas públicas ineficientes e a grande produção de recipientes descartáveis elevaram consideradamente o número de potenciais criadouros para o mosquito (TAUIL 2001). Historicamente, este fato e o início do crescimento desordenado das cidades brasileiras nesta época, coincidem com o reaparecimento da espécie em diversos municípios brasileiros. Desde então o número de municípios com infestação por Ae. aegypti é crescente (BARRETO et al. 2011).

O Aedes albopictus (Skuse) possui uma história mais recente, foi encontrado pela primeira vez no continente sul-americano, mais especificamente identificado no Brasil em 1986. Por ser de origem asiática, aparentemente sua presença em território nacional foi influenciada pelo comércio com países do sudeste asiático

Agência de Financiamento: FAPERJ (PIBIC) e USS (PIBIC) 
T (Forattini 1986). Diferente do Ae. aegypti, o Ae. albopictus não depende de grandes concentrações humanas, embora se aproveitem dos mesmos criadouros. Nas Américas embora alguns estudos tenham encontrado Ae. albopictus naturalmente infectados, eles não foram apontados como vetor da dengue (SCHATZMAYR 2000).

$O$ Ae. albopictus possui uma maior resistência ao frio que o $A e$. aegypti, podendo atingir regiões do planeta, que vão de $45^{\circ} \mathrm{N}$ a $40^{\circ} \mathrm{S}$, ocorrendo naturalmente em regiões de clima temperado e tropical. Sendo muito menos doméstico que o Ae. aegypti ficou mais adaptado aos ambientes rurais, suburbanos e urbanos, o Ae. albopictus possui uma maior dispersão pelo voo, e fazem uso de criadouros naturais o que o torna independente em relação às grandes concentrações humanas, além de também utilizarem recipientes artificiais comumente utilizados pelos Ae. aegypti (CONSOli \& LOURENÇO-DE-Oliveira 1994).

Diante dos consecutivos casos de dengue no município de Vassouras, ocorridos principalmente no período de maior incidência pluviométrica, tornou-se importante verificar em campo a dinâmica populacional do vetor em diversas épocas do ano e principalmente sua correlação com a espécie silvestre, Ae. albopictus, que é um importante vetor dos ciclos naturais de arboviroses (LOURENÇO-DE-OLIVEIRA et al. 2003).

\section{MATERIAL E MÉTODOS}

As coletas foram realizadas em quatro pontos (Figura 1) da cidade de Vassouras - RJ (23 ${ }^{\circ} 24^{\prime} 14$ "S, $43^{\circ} 39$ ' $\left.45^{\prime \prime} \mathrm{W}\right)$ durante o período de janeiro de 2011 a dezembro de 2012. Estes pontos foram indicados por estudos anteriores realizados com o levantamento de larvas de Ae. aegypti e Ae. albopictus como pontos críticos para a presença de larvas dos culicídeos e confirmados pela vigilância sanitária da Secretaria Municipal de Saúde, pela sua relevância na incidência de casos de dengue.

O ponto 1 de coleta está situado no centro da cidade e serviu como referencial para os demais pontos de coleta. O ponto 2 está localizado a um bairro próximo ao centro, bairro Residência, e que possui uma maior concentração de domicílios. O ponto 3 referese ao cemitério municipal e que está localizado no bairro Campo Limpo. Este local possui uma menor concentração de residências quando comparado ao bairro Residência citado anteriormente. O ponto 4 é o local de coleta mais afastado do centro da cidade, bairro Matadouro, e o menos habitado.

As coletas foram realizadas através do uso de armadilhas do tipo "ovitrampas". Estas armadilhas consistiram em um vaso de plástico para plantas de 10 x 7,5 cm, e este revestido com papel do tipo craft como suporte de depósito de ovos dos mosquitos, e preenchidas por três quartos de água da torneira, sem qualquer atrativo em especial para o mosquito. As armadilhas foram instaladas a altura entre 1,00 e 1,50 m do solo.

As coletas foram realizadas semanalmente, e os suportes de papel e água substituídos. A temperatura e umidade ambiente foram registradas a cada troca do material da armadilha, com o auxílio de termômetro digital (Termo-Higrômetro 7666.02) previamente estabilizado ao ambiente por $5 \mathrm{~min}$.

Os suportes de papel com ovos coletados foram levados ao Laboratório de Insetos Vetores da Universidade Severino Sombra, identificados e armazenados em recipientes plásticos à temperatura ambiente. E, assim preservados até sua utilização e estudo. Os ovos foram cuidadosamente analisados, e contados com a utilização de um contador de colônias (Fenix, CP602).

Para a eclosão dos ovos, os suportes de papel previamente armazenados foram colocados em recipientes contendo $500 \mathrm{~mL}$ de água sem cloro até próximo a superfície, e posteriormente colocados em incubadora (BOD - CP 703) a $28^{\circ} \mathrm{C} \pm 1$.

Cada recipiente contendo ovos para eclodir permaneceu vedado com tecido fino a fim de manter a oxigenação da água, proteger contra a entrada de invasores e não permitir a liberação do inseto caso ocorresse a emergência (Figura 2), o descarte foi feito imergindo o suporte de papel em álcool etílico a 92,8\% por um

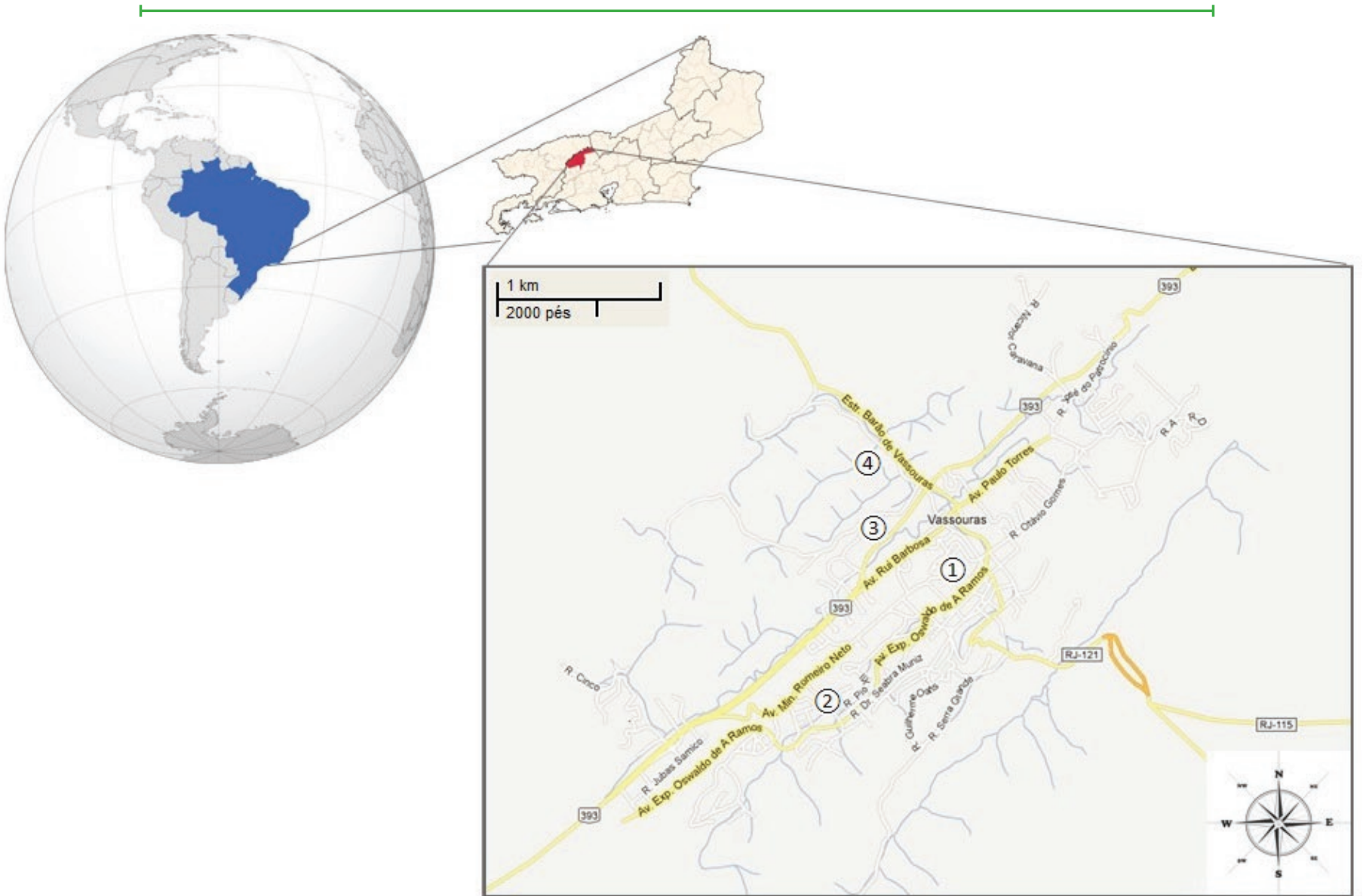

Figura 1. Pontos de coleta de ovos dos mosquitos no município de Vassouras, RJ. Mapa adaptado de Google Maps em Julho/2012. 

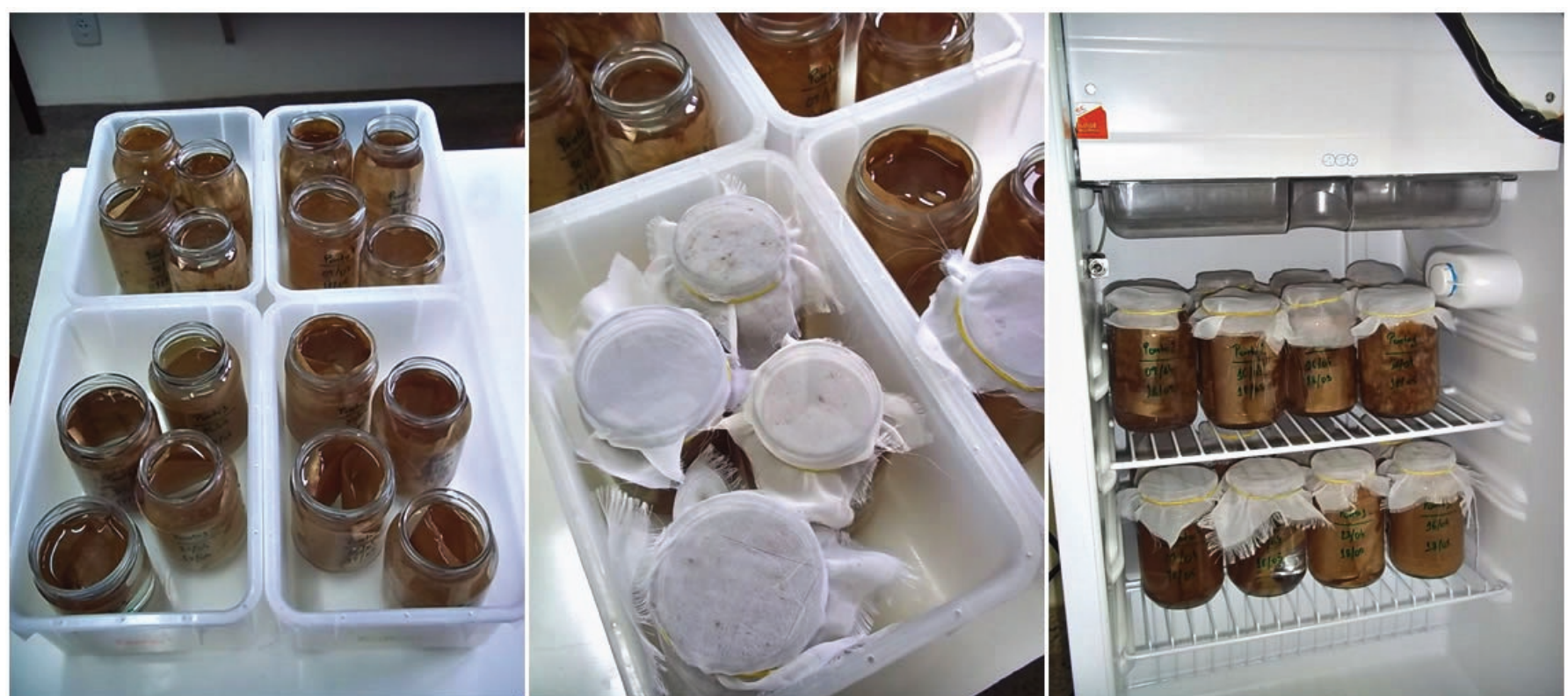

Figura 2. Metodologia utilizada para eclosão de ovos de Aedes em laboratório utilizando a incubadora.

período de 1 hora, a fim de inviabilizar os ovos não eclodidos.

Os recipientes foram analisados a cada dois dias após o inicio da eclosão por um período de 2 semanas. Quando da presença de larvas no terceiro estágio (L3), estas foram separadas com o auxílio de pipeta e colocadas em placas de Petri contendo álcool etílico a 70\% para sua mortalidade. As larvas mortas (L3) foram preparadas em lâminas e identificadas ao microscópio óptico (Coleman XSZ107BN) objetiva em 10X. Para avaliar a presença de ovos associados à umidade relativa do ar foram utilizadas correlações não paramétricas de Spearman $\left(\mathrm{r}_{\mathrm{s}}\right)$ utilizando $\mathrm{o}$ programa BioEstat 5.0, no teste foi utilizado $\alpha=0,05$.

\section{RESULTADOS}

Os resultados mostraram de janeiro de 2011 a dezembro de 2012 um percentual de 15,60\% (364) de ovos viáveis dos 2333 coletados, com 89,56\% (326) de presença de Ae. albopictus e de 10,44\% (38) de Ae. aegypti (Figura 3) e o número mensal de ovos coletados nos 4 pontos distribuídos no município, a quantidade de larvas eclodidas a partir destes ovos, a média da temperatura e da umidade relativa do ar registradas no momento da coleta (Tabela 1).

Quanto aos locais de coleta, a soma da quantidade de ovos encontrada nos pontos 1, 2 e 3 foi menor que o total encontrado apenas no ponto 4, ponto de coleta mais distante em relação ao centro da cidade. Neste local o número de ovos coletados foi de 1.333 perfazendo um total de (57\%) ovos de mosquitos (Figura 4), e destes $18,98 \%$ tornaram-se viáveis, sendo 1,43\% (19) de Ae. aegypti e 17,55\% (234) de Ae. albopictus.

Quanto à distribuição dos ovos no período e correlacionada à temperatura e umidade média registrada no decorrer dos meses, observou-se que o maior número de ovos coletados ocorreu nos meses de janeiro e março de 2011 e abril de 2012, meses estes com o maior índice de umidade (Figura 5).

Quando os números absolutos de eclosão de cada espécie em cada mês de coleta foram analisados, observou-se que Ae. aegypti esteve mais presente nos meses de janeiro e abril de $2011 \mathrm{com}$ umidade compreendida entre 45-60\% e Ae. albopictus nos meses abril e junho de 2012 com umidade acima de 50\% (Figura 6).

Os meses de janeiro e abril de 2011 houve um índice relevante de 14 e 15 ovos eclodidos respectivamente da espécie Ae. aegypti, e nos meses de abril e junho de 2012 presença de 114 e 81 ovos eclodidos respectivamente da espécie Ae. albopictus (Figura 7).

Os dados das associações de fatores como temperatura e umidade foram significantes para os ovos coletados em relação à umidade $(\mathrm{p}=0,04)$ e em relação à temperatura $(\mathrm{p}=0,03)$. A espécie Ae. albopictus obteve o valor de associação mais alto e expressivamente relevante quando comparado com a umidade

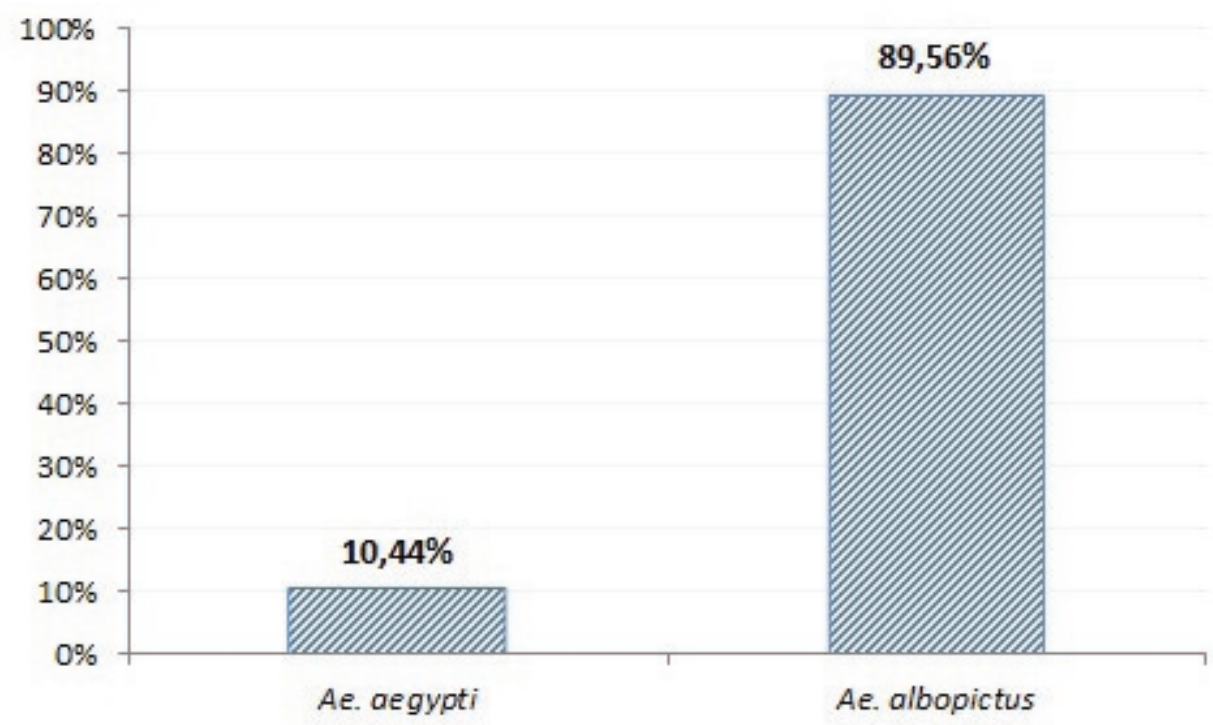

Figura 3. Frequência das espécies Ae. aegypti e Ae. albopictus encontradas em ovos viáveis. 

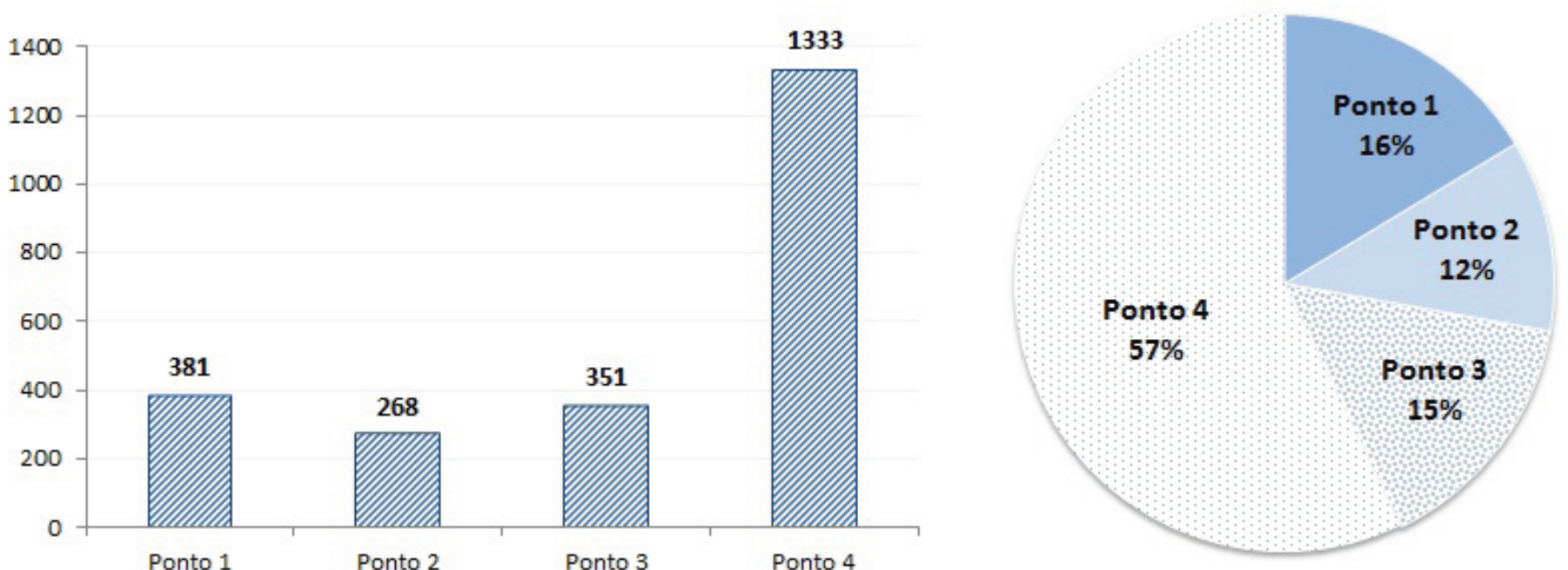

Figura 4. Valores absolutos e relativos do total de ovos para cada um dos quatro pontos de coleta no município de Vassouras, RJ.

Tabela 1. Número de ovos de Ae. aegypti e Ae. albopictus no período de janeiro de 2011 a dezembro de 2012 encontrados nos quatro pontos de coleta, no município de Vassouras, RJ.

\begin{tabular}{|c|c|c|c|c|c|}
\hline Mês & Ovos & Ae. aegypti & Ae. albopictus & $\begin{array}{c}\text { Temp. Media } \\
\left({ }^{\circ} \mathrm{C}\right)\end{array}$ & Umid. Média (\%) \\
\hline Jan/11 & 512 & 14 & 40 & 32,8 & 58,7 \\
\hline Fev/11 & 62 & o & 2 & 30,2 & 37,0 \\
\hline Mar/11 & 281 & o & 33 & 27,3 & 52,3 \\
\hline $\mathrm{Abr} / 11$ & 146 & 15 & 22 & 27,2 & 42,7 \\
\hline Mai/11 & 34 & 1 & 9 & 23,1 & 45,1 \\
\hline Jun/11 & 44 & o & 0 & 23,2 & 48,9 \\
\hline $\mathrm{Jul} / 11$ & 35 & o & o & 23,1 & 36,4 \\
\hline Ago/11 & 22 & o & 0 & 28,5 & 25,8 \\
\hline Set/11 & 42 & o & $\mathrm{O}$ & 25,8 & 25,7 \\
\hline Out/11 & 21 & o & o & 25,4 & 37,2 \\
\hline Nov/11 & 73 & o & o & 26,1 & 38,2 \\
\hline Dez/11 & 69 & 1 & 0 & 26,1 & 40,8 \\
\hline Jan/12 & 38 & $\mathrm{O}$ & $\mathrm{O}$ & 26,4 & 47,3 \\
\hline Fev/12 & 109 & o & 0 & 28,3 & 37,8 \\
\hline Mar/12 & 90 & o & 4 & 25,8 & 57,3 \\
\hline $\mathrm{Abr} / 12$ & 372 & 4 & 114 & 26,1 & 53,3 \\
\hline Mai/12 & 16 & o & 3 & 21,8 & 56,3 \\
\hline Jun/12 & 128 & o & 81 & 24,1 & 63,1 \\
\hline Jul/12 & 19 & 1 & 3 & 22,3 & 70,3 \\
\hline Ago/12 & 51 & o & 0 & 25,5 & 66,7 \\
\hline Set/12 & 50 & 2 & 15 & 26,6 & 47,1 \\
\hline Out/12 & 39 & o & o & 28,4 & 44,9 \\
\hline Nov/12 & 53 & o & $\mathrm{O}$ & 26,9 & 48,6 \\
\hline Dez/12 & 27 & 0 & 0 & 29,3 & 56,1 \\
\hline Total & 2333 & 38 & 326 & & \\
\hline
\end{tabular}

relativa do ar $\left(\mathrm{p}=0,0007\right.$ e $\left.\mathrm{r}_{\mathrm{s}}=0,7244\right)$. Entretanto para a espécie Ae. aegypti não foi detectada valor expressivo comparando-a com as médias de umidade do ar e temperatura ambiente.

\section{DISCUSSÃO}

10 Os resultados mostraram uma acentuada presença da espécie Ae. albopictus em relação ao Ae. aegypti na cidade de Vassouras - RJ, e demonstraram a afinidade da espécie por ambientes suburbanos com ampla cobertura vegetal e recipientes artificiais HaWley (1988). Conforme descrito por SoAREs et al. (2008) e
BARBosa et al. (2010) essas características são típicas da maioria das cidades do interior do Estado do Rio de Janeiro em específico na região Centro Sul Fluminense, onde a distância entre o bairro central do município e a periferia ou zona rural acaba não sendo tão longa.

A presença de Ae. aegypti foi no bairro com maior número de residências (ponto 2) com 4,85\% dos ovos eclodidos, porém ainda menor que a presença da espécie Ae. albopictus com 7,46\% dos ovos eclodidos, mesmo sendo este o ponto com menor quantidade 


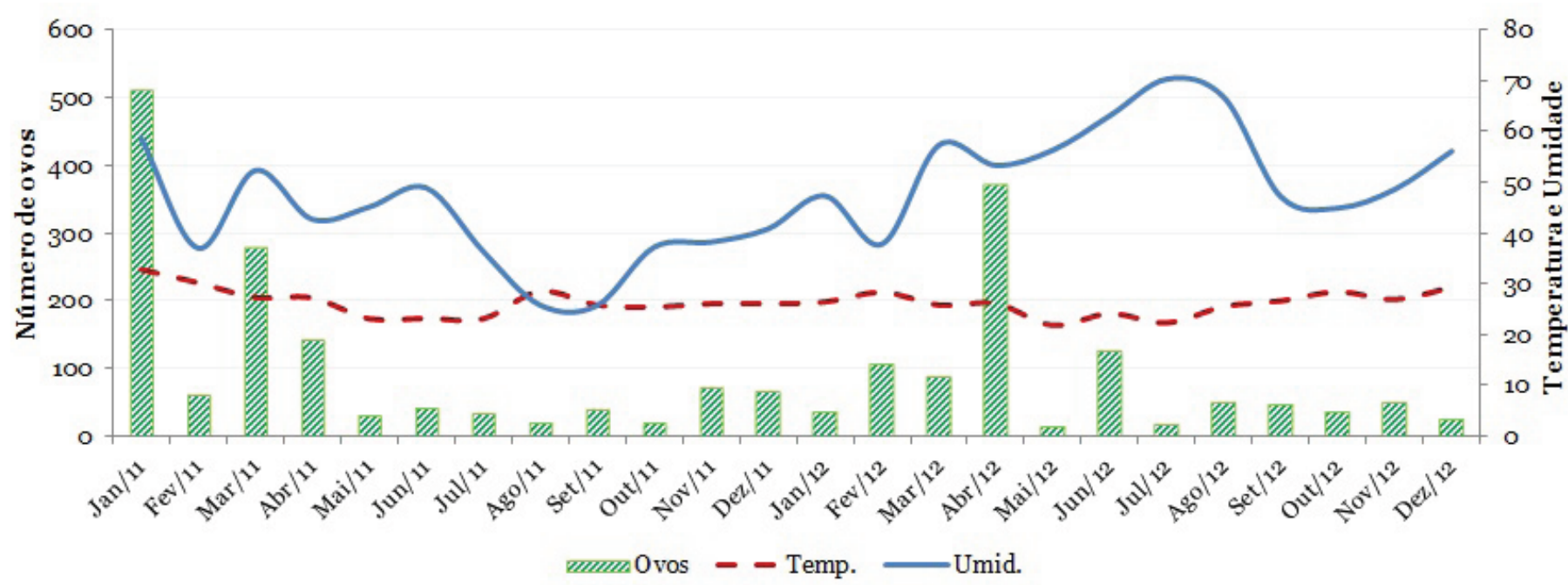

Figura 5. Número total de ovos coletados por mês correlacionados a temperatura e umidade relativa do ar.

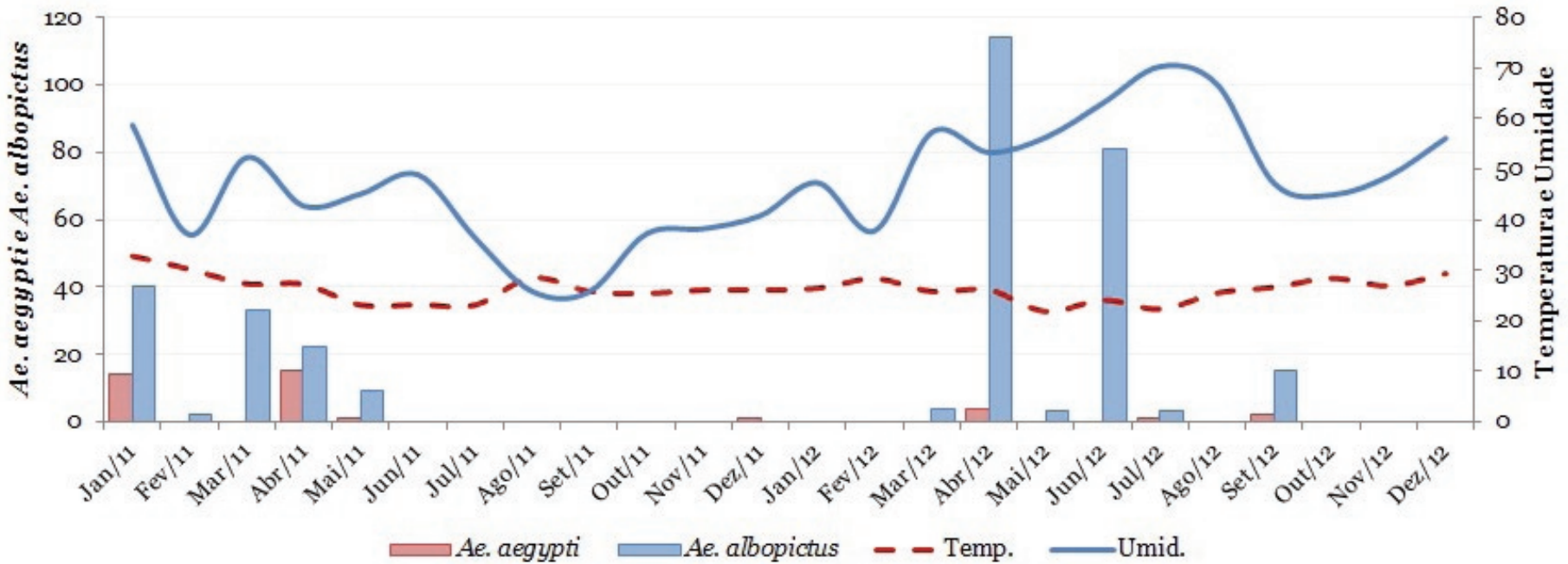

Figura 6. Número de espécimes de Ae. aegypti e Ae. albopictus encontrados por mês, correlacionados a temperatura e a umidade relativa do ar.

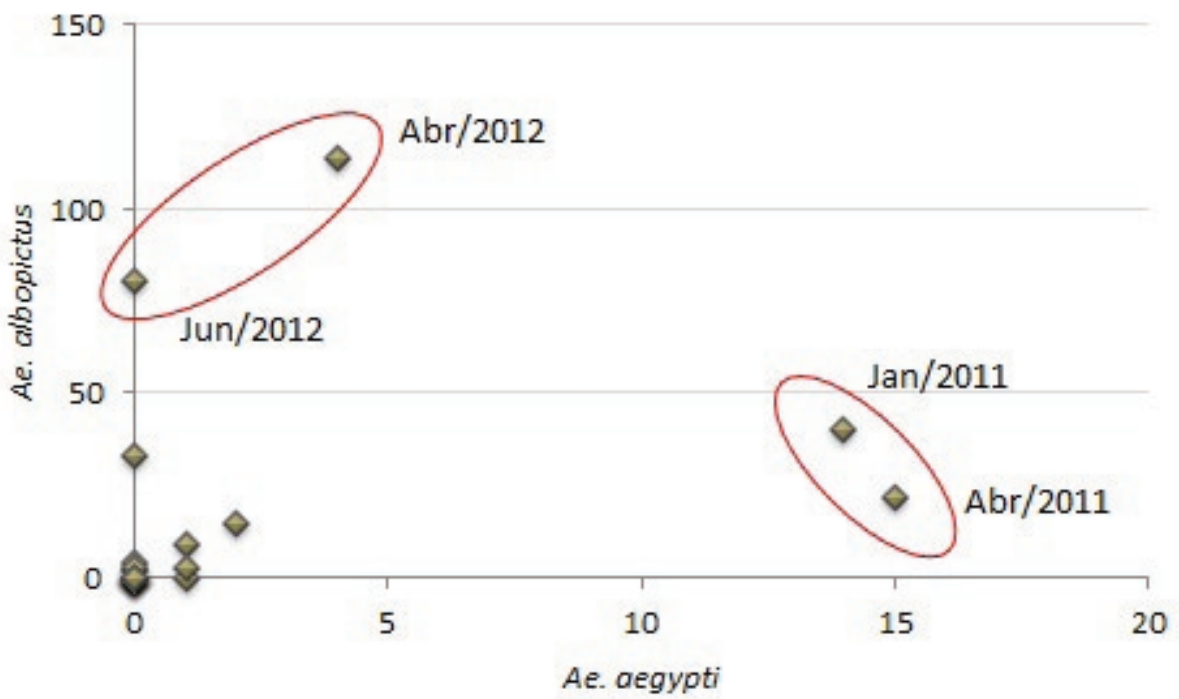

Figura 7. Dispersão das espécies no período entre janeiro de 2011 e dezembro de 2012 no município de Vassouras, RJ.

de ovos coletados 268 (12\%). Urbinatti (2004) evidencia a valência ecológica da espécie Ae. albopictus, em colonizar ambientes naturais e artificiais, tanto em áreas protegidas como em áreas alteradas.

Quando comparado todo o período de coleta e registradas as condições de temperatura e a umidade do ar, verificou-se o aumento da postura de ovos nos períodos em que as médias de umidade relativa do ar e da temperatura atingiram índices mais elevados, como descritos por EstradA-FrANCO \& CRAIG (1995) para a espécie Ae. albopictus e KEARNEY et al. (2009) para a espécie Ae. aegypti. Ao verificar a relevância entre as duas espécies do estudo, observou-se um maior favorecimento à presença de Ae. aegypti no ano de 2011 em relação ao ano de 2012, porém ainda inferior a 
Através do teste não paramétrico de Spearman verificou-se a alta relação da espécie Ae. albopictus e a umidade relativa do ar média registrada nos meses de estudo, entretanto essa relação não foi significativa para a temperatura média $\left(\mathrm{r}_{\mathrm{s}}=0,086\right)$, o mesmo ocorrendo com a espécie Ae. aegypti para os dois parâmetros (umidade relativa $r_{s}=0,268$ e temperatura $r_{s}=0,208$ ) em que não ficou evidenciado devido ao número baixo de imaturos obtidos após eclosão em laboratório, e recentemente comprovada a superioridade competitiva das larvas de Ae. albopictus (Juliano et al. 2004).

A queda no número de ovos eclodidos da espécie Ae. aegypti no ano posterior pode estar relacionada às medidas de combate ao vetor do vírus da dengue adotadas após o grande surto de casos no verão do mesmo ano, vindo a refletir nos resultados para o ano seguinte.

A armadilha diferenciada, especialmente projetada para este experimento, mostrou-se altamente eficaz, entretanto estudos sobre afinidade das espécies em relação à postura ainda devem ser realizados.

Ambas as espécies mostraram-se perfeitamente adaptadas ao ambiente e clima do município de Vassouras-RJ, com maior densidade de espécimes de Ae. albopictus o que parece ser favorecido pela presença de abundantes áreas silvestres ao redor da cidade.

Com o aumento da umidade relativa do ar em um mês atípico (junho/2012), e queda em mês tipicamente úmido (fevereiro/2011), evidenciaram-se as relações entre as posturas de ovos realizadas nas armadilhas e as condições climáticas.

\section{REFERÊNCIAS}

Barbosa, P.R.M., W.C. Rodrigues \& M.M.O. Cabral, 2010. Incidência das Formas Imaturas de Aedes albopictus (Skuse) e Aedes aegypti (Linnaeus) no Município de Miguel Pereira, RJ, Brasil. EntomoBrasilis, 3: 55-58.

Barreto, M.L., M.G. Teixeira, F.I. Bastos, R.A.A. Ximenes, R.B. Barata \& L.C. Rodrigues, 2011. Sucessos e fracassos no controle de doenças infecciosas no Brasil: o contexto social e ambiental, políticas, intervenções e necessidades de pesquisa. The Lancet. Série Saúde no Brasil 3: 47-6o. Disponível em: $<$ http://download.thelancet.com/flatcontentassets/pdfs/ brazil/brazilpor3.pdf $>$.

Braga, I.M. \& D. Vale, 2007. Aedes aegypti: histórico do controle no Brasil. Epidemiologia e Serviços de Saúde, 16: 113-118.

Consoli, R.A.G.B. \& R. Lourenço-de-Oliveira, 1994. Principais Mosquitos de Importância Sanitária no Brasil. Rio de Janeiro, Editora Fiocruz, 228p.

\section{Como citar este artigo:}

Oliveira, A.A. \& M. Maleck, 2014. Ovitrampas para Avaliação da Presença de Aedes aegypti (Linnaeus) e Aedes albopictus (Skuse) no Município de Vassouras, Estado do Rio de Janeiro. EntomoBrasilis, 7 (1): 52-57.

Acessível em: doi:10.12741/ebrasilis.v7i1.369
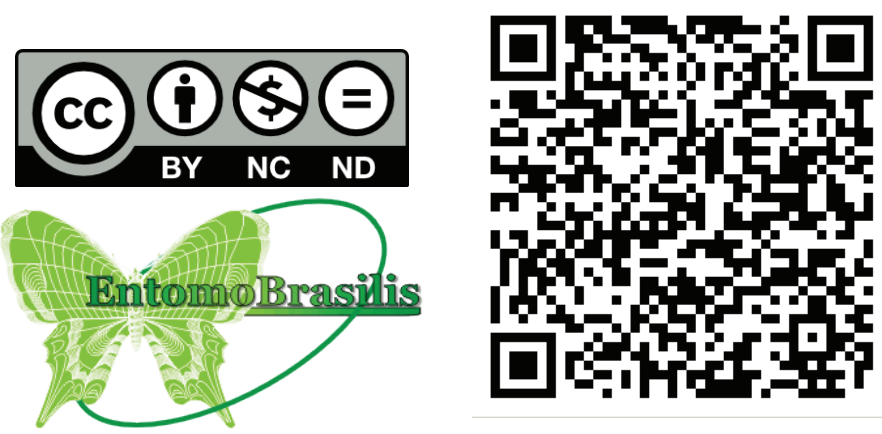